\title{
Article
}

\section{Physical and Economic Potential of Geological CO Storage in Saline Aquifers}

Jordan K. Eccles, Lincoln Pratson, Richard G. Newell, and Robert B. Jackson

Environ. Sci. Technol., Article ASAP • DOI: 10.1021/es801572e • Publication Date (Web): 06 February 2009

Downloaded from http://pubs.acs.org on February 11, 2009

\section{More About This Article}

Additional resources and features associated with this article are available within the HTML version:

- $\quad$ Supporting Information

- $\quad$ Access to high resolution figures

- $\quad$ Links to articles and content related to this article

- Copyright permission to reproduce figures and/or text from this article

\section{View the Full Text HTML}


Physical and Economic Potential of Geological $\mathrm{CO}_{2}$ Storage in Saline Aquifers

\author{
J O R A N K. ECCLES, *, † \\ LINCOLN PRATSON, ${ }^{\dagger}$ \\ RICHARD G. NEWELL, ${ }^{\dagger}$ A N D \\ ROBERT B. JACKSON ${ }^{\dagger}$, \\ Nicholas School of the Environment, Division of Earth and \\ Ocean Sciences and Center on Global Change, Duke \\ University, Durham, North Carolina 27708
}

Received June 8, 2008. Revised manuscript received November 10, 2008. Accepted January 5, 2009.

Carbon sequestration in sandstone saline reservoirs holds great potential for mitigating climate change, but its storage potential and cost per ton of avoided $\mathrm{CO}_{2}$ emissions are uncertain. We develop a general model to determine the maximum theoretical constraints on both storage potential and injection rate and use it to characterize the economic viability of geosequestration in sandstone saline aquifers. When applied to a representative set of aquifer characteristics, the model yields results that compare favorably with pilot projects currently underway. Over a range of reservoir properties, maximum effective storage peaks at an optimal depth of $1600 \mathrm{~m}$, at which point $0.18-0.31$ metric tons can be stored per cubic meter of bulk volume of reservoir. Maximum modeled injection rates predict minima for storage costs in a typical basin in the range of \$2-7/ ton $\mathrm{CO}_{2}$ (2005U.S. \$) depending on depth and basin characteristics in our base-case scenario. Because the properties of natural reservoirs in the United States vary substantially, storage costs could in some cases be lower or higher by orders of magnitude. We conclude that available geosequestration capacity exhibits a wide range of technological and economic attractiveness. Like traditional projects in the extractive industries, geosequestration capacity should be exploited starting with the low-cost storage options first then moving gradually up the supply curve.

\section{Introduction}

One potential strategy to mitigate global climate change is to capture the carbon dioxide that would normally be emitted from fossil fuel burning and sequester it in long-term, stable reservoirs. Many of the world's energy markets (including that of the United States) are likely to have some kind of emissions control program that will impose a cost on greenhouse gas (GHG) emissions as in the European Union. If the cost imposed on a firm for emitting carbon is more than the cost of capturing and sequestering it and if the size of storage reservoirs is great enough to store a significant amount of captured carbon, the technology could be effective at mitigating climate change while allowing the continued use of fossil fuels (1).

One important factor in the cost of sequestration is variability in the storage potential of sedimentary basins.

\footnotetext{
* Corresponding author phone: (919) 681-6577; fax: (919) 6845833; email: jordan.eccles@duke.edu.

${ }^{\dagger}$ Division of Earth and Ocean Sciences, Duke University.

${ }^{*}$ Center on Global Change, Duke University.
}

Deep saline aquifers have been proposed as a type of reservoir with significant storage potential as they tend to be permeable sandstones and generally occur at depths where the pressure and temperature would keep carbon dioxide in a very dense supercritical state.

Interest in these reservoirs assumes that the capacity will be large and the costs of carbon capture and storage will be competitive with alternative emissions mitigation strategies. The IPCC Special Report on Carbon Sequestration (1) cites three primary sources for the estimated cost of geosequestration in deep saline aquifers: Bock (2002) (2), Hendriks (2002) (3), and Allinson (2003) (4). These analyses have made generalizations that may oversimplify key variables that have significant effects on $\mathrm{CO}_{2}$ storage potential. Static storage potential per unit volume in a given reservoir depends not only on the density (which varies with temperature and pressure $1,2,5,6$ ) but also on reservoir porosity (i.e., void space). Additionally, some of these studies did not consider variables that affect the rate at which $\mathrm{CO}_{2}$ can be pumped into the reservoir. Where injection rates are considered (2) they are derived from numerical simulations. In reality, layer thickness, permeability, and depth will likely have large effects on injection rates, and these properties can vary by several orders of magnitude among and within reservoirs.

In this paper, we develop a general analytic model to place bounds on the storage potential and rate at which $\mathrm{CO}_{2}$ can be sequestered in permeable geologic reservoirs. For this analysis we use the model to assess the potential of saline aquifers in sandstone sedimentary units, estimating the maximum storage potential and injection rates of these reservoirs as well as the minimum resulting cost per metric ton $\mathrm{CO}_{2}$ of storage (all tons hereafter are metric tons). We compare and calibrate our model results with three deep saline aquifer injection pilot projects: Nagaoka, Japan, the Frio formation in Texas, and Norway's Sleipner West field in the North Sea. Finally, we apply the model to estimate a range of geosequestration costs for a group of sedimentary basins throughout the United States.

\section{Analytical Model}

The elements of geosequestration addressed by our model are depicted schematically in Figure 1. In the model we assume that the $\mathrm{CO}_{2}$ to be injected underground is already in a supercritical state having a temperature, pressure, and density of $T_{\text {crit }}, P_{\text {crit }}$, and $\rho_{\text {crit }}$, respectively. In our application of the model, this $\mathrm{CO}_{2}$ is piped down a well into a tabular sandstone saline reservoir of thickness $b$ (meters) sealed above and below by impermeable strata. The model developed to analyze this system has three components, explained in the following sections.

2.1. Component 1: Maximum $\mathrm{CO}_{2}$ Storage Potential. The $\mathrm{CO}_{2}$ storage potential of a saline reservoir varies with depth in at least three ways. As reservoir depth increases, pressure increases, increasing $\mathrm{CO}_{2}$ density and thus the effective storage potential of the reservoir. However, temperature also increases with depth, reducing density, and as overburden pressure increases, reservoir porosity is reduced, causing an offsetting reduction in effective storage potential (7).

We model these changes over a range of depths. Temperature and pressure are used to determine the density of the sequestered supercritical $\mathrm{CO}_{2}$, while the available void space to be occupied by this fluid depends on porosity.

We use a linear approximation of the relationship between temperature and depth (8), i.e.

$$
T(z)=T_{\mathrm{o}}+c_{1} z
$$

VOL. $x x x$, NO. $x x, x X X X$ / ENVIRONMENTAL SCIENCE \& TECHNOLOGY — A 


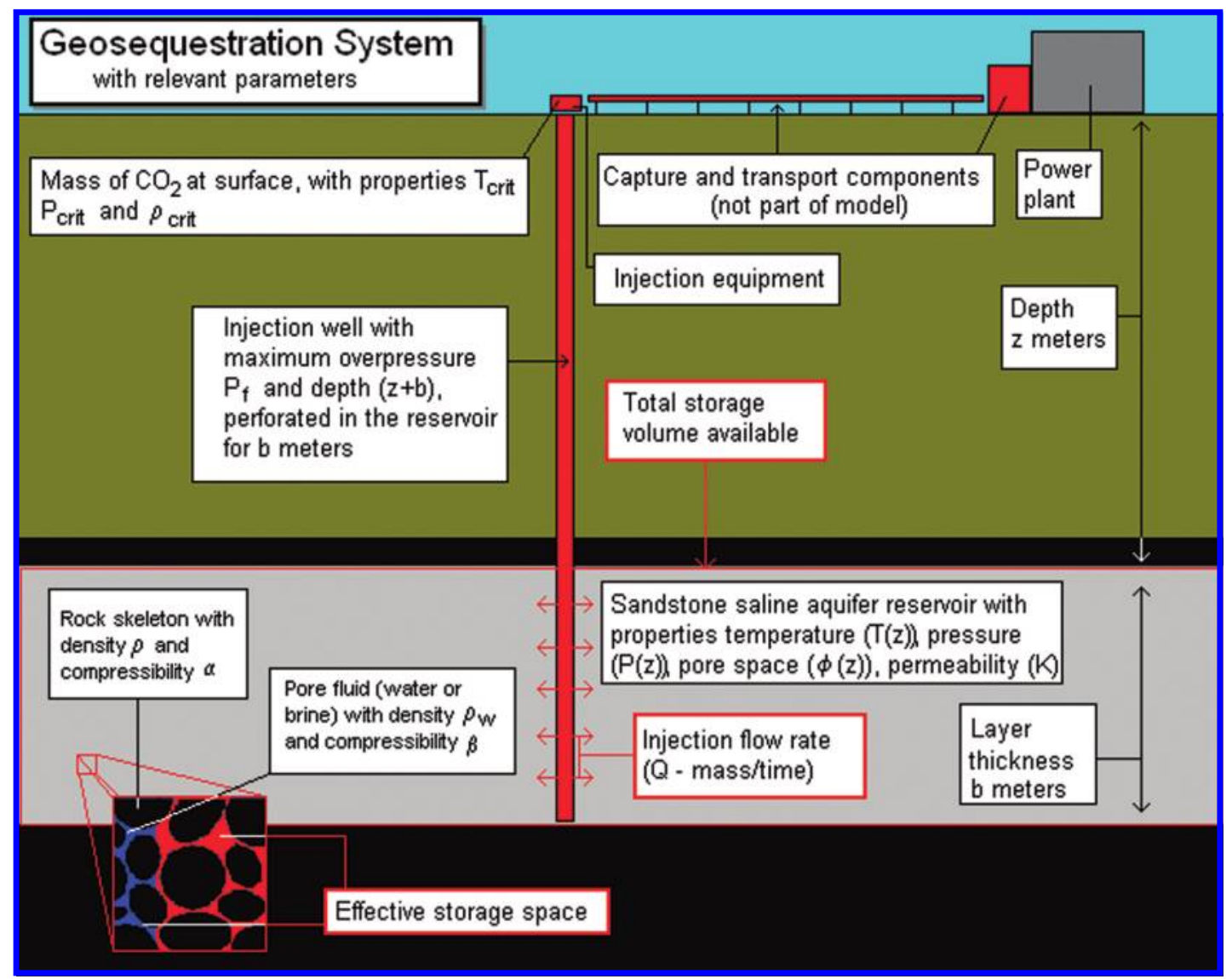

FIGURE 1. Schematic diagram of the geosequestration system. The geosequestration system consists of capture, transport, and sequestration components of which the model only considers sequestration. Shown here are the relevant characteristics considered in the model.

Here, $T_{0}$ is temperature at the surface, $c_{1}$ is the temperature gradient, and $z$ is the depth.

We also model the relationship between pressure and depth as linear under hydrostatic conditions. The relationship can be expressed as

$$
P(z)=\rho_{\mathrm{w}} g\left(z-z_{0}\right)
$$

where $\rho_{\mathrm{w}}$ is the density of the fluid column, $g$ is the acceleration of gravity, and $z_{0}$ is the depth of the water table (9). Note that as salinity and thus density of the pore water increases in eq 2, so does pressure.

Porosity decreases with depth at an exponential rate, defined by Athy's Law (7)

$$
\varphi(z)=\varphi_{0} e^{-c_{3} z}
$$

where $\phi_{0}$ is the porosity at the surface and $c_{3}$ is an empirically determined constant.

As with temperature and pressure, porosity varies considerably in strata even at a particular depth. However, while local variation in porosity will change the magnitude of the storage potential function, it will not significantly change the function's shape as the gradient depends on overburden pressure.

Finally, we use the standard Boyle's and Charles' Laws for gases to account for changes in the density of the supercritical $\mathrm{CO}_{2}$ fluid as it enters different temperature and/ or pressure zones in the reservoir. Although these laws do not hold over the nonlinear transition to supercritical state (5), the behavior of supercritical fluid is essentially that of an ideal gas under most of the temperature and pressure regimes considered; in deeper reservoirs, this approximation will overestimate density. Effective storage is further constrained by available void space. Together, the model combines these laws with eq 3 to arrive at the following equation for maximum effective storage potential ( $V_{\mathrm{e}}$, e.g., measured on a volume $\mathrm{CO}_{2}$ per volume reservoir basis) at a given depth

$$
V_{\mathrm{e}}=\frac{T_{\text {crit }}}{P_{\text {crit }}} \cdot \frac{P(z)}{T(z)} \cdot \varphi(z)
$$

Equation 4 is the maximum effective storage potential of the void space in the rock irrespective of the temporal evolution of the $\mathrm{CO}_{2}$ plume if the total pore volume is filled solely with $\mathrm{CO}_{2}$ only (a condition which is unlikely to occur in most of the bulk volume of the reservoir (1)).

2.2. Component 2: Maximum $\mathrm{CO}_{2}$ Injection Rate. The maximum rate at which $\mathrm{CO}_{2}$ can be discharged into a reservoir is limited in theory by the injection-induced pressure that would cause hydraulic fracturing beyond the perforated zone around the well. Hydraulic fracturing is dictated by the difference between the overburden stresses compressing the rock matrix together and the fluid pressure from within the pores pushing out on the matrix as it is being squeezed. Hydraulic fracture occurs when the pore pressure is high enough that the state of effective stress, i.e.

$$
\begin{gathered}
\sigma_{n}=\left(\frac{\sigma_{1}+\sigma_{3}-P_{\mathrm{f}}}{2}\right)+\left(\frac{\sigma_{1}-\left(\sigma_{3}-P_{\mathrm{f}}\right)}{2}\right) \cos (2 \theta) \\
\sigma_{\mathrm{T}}=\left(\frac{\sigma_{1}-\left(\sigma_{3}-P_{\mathrm{f}}\right)}{2}\right) \sin (2 \theta)
\end{gathered}
$$

for any plane of fracture (defined by the angle $\theta$ ) reaches the Mohr-Coulomb failure criterion

$$
\sigma_{\mathrm{T}}=\tau_{\mathrm{s}}+\sigma_{\mathrm{n}} \mu
$$


In these equations, $\sigma_{\mathrm{n}}$ is the normal stress due to overburden pressure $\sigma_{1}$ and the tensional stress $\sigma_{\mathrm{T}}$, which includes both hydrostatic pressure $\left(\sigma_{3}\right)$ and any additional pore pressure due to injection $\left(P_{\mathrm{f}}\right) . \tau_{\mathrm{s}}$ is the shear strength of the rock matrix, and $\mu$ is the friction coefficient, both of which are empirically determined constants (10).

Our model solves eqs 5-7 for $P_{\mathrm{f}}$, which is the maximum overpressure the reservoir can bear before fracturing. The pressure is converted to a volumetric rate from the injection well using a solution of Darcy's law known as the Theis well function (9)

$$
\begin{gathered}
X=K b \\
S=S_{\mathrm{s}} b \\
\mathrm{~S}_{\mathrm{s}}=\rho_{\mathrm{w}} g(\alpha+\varphi(z) \beta) \\
u=\frac{S}{4 X} f \\
Q_{\mathrm{vol}}=\frac{-P_{\mathrm{f}} 4 \pi X f}{g \rho E i(u)}
\end{gathered}
$$

Equation 8 determines the transmissivity $(X)$ of the reservoir as a function of hydraulic conductivity $(K)$ and layer thickness (b). Equation 9 determines the storativity $(S)$ of the reservoir as a function of the specific storativity of the material composing the reservoir $\left(S_{\mathrm{s}}\right)$ and its thickness $(b)$, where specific storativity is calculated with eq 10 (storativity is not related to effective storage potential). Equation 10 shows that specific storativity is a function of the density of water and the acceleration of gravity, the compressibility of the rock skeleton $(\alpha)$, the porosity of the reservoir $(\phi)$, and the compressibility of water $(\beta)(9)$.

The Theis well function in eq 12 relates volumetric flux to the pressure differential $\left(P_{\mathrm{f}}\right)$ between two locations (in this case the well and the background pressure of the reservoir) as well as parameters from eqs $8-11 . f$ in eq 11 describes the zone of influence in which fracture is permitted spatially and temporally (9).

Equation 12 uses the pressure $\left(P_{\mathrm{f}}\right)$ from eqs $5-7$ to determine the maximum rate at which a fluid can be injected before major fracturing of the reservoir rock will occur. We calculate an approximate absolute permeability using

$$
k=\sqrt{k_{\mathrm{h}} k_{\mathrm{v}}}
$$

where the vertical permeability $\left(k_{v}\right)$ is 0.3 times the horizontal permeability $\left(k_{\mathrm{h}}\right)$ for anisotropic reservoirs, although this ratio of vertical to horizontal permeability can vary among anisotropic reservoirs (11). Permeability is converted to hydraulic conductivity $(K)$ for eq 8 (9). Equation 12 is not modified for two-phase flow, so viscosity, miscibility, and buoyancy are not taken into account. These factors should most affect viscous fingering, dissolution, and vertical plume evolution, however, and in this type of flow compressibility along the flow path will be negligible (12). In thick layers, the density of the gas in the fluid column relative to the reservoir pore fluid means that the pressure differential between the injection well and the reservoir pore pressure over the layer is not constant. A correction factor is applied to account for this when necessary.

Finally, the results of eq 12 are converted to a mass rate. This is accomplished using the local temperature and pressure to compute the corresponding local supercritical fluid density, i.e.

$$
Q_{\text {mass }}=\rho_{\text {crit }} \frac{T_{\text {crit }}}{P_{\text {crut }}} \frac{P(z)}{T(z)} Q_{\text {vol }}
$$

2.3. Component 3: Cost per Ton of $\mathrm{CO}_{2}$ Geosequestration. The last component of our model is an economic analysis of the cost of injection in terms of cost per emissions stored. We construct a relationship between the total cost of a geosequestration project and the emissions stored to arrive at a cost per ton of $\mathrm{CO}_{2}$. We estimate the capital cost and operations and maintenance (O\&M) cost of these wells amortized over a project lifetime to compute total costs. Note that a distinction arises between emissions "stored" and "avoided" because there is an energy penalty to capturing and transporting the $\mathrm{CO}_{2}$ to the injection site. Since the entire carbon capture and sequestration (CCS) system must be evaluated to consider emissions avoided rather than emissions stored (1), we evaluate the geosequestration component with a cost per emissions stored to permit integration with different capture technologies or $\mathrm{CO}_{2}$ transport requirements.

We determine average cost for sequestration on a singlewell basis (rather than a firm-level cost estimate since variables such as emissions rates are essentially arbitrary unless studies of specific firms are undertaken). Total costs are assumed to be a combination of drilling, injection equipment, and O\&M costs. Drilling and injection equipment costs increase nonlinearly with depth as given by the quadratic functions

$$
\begin{gathered}
C_{\text {drill }}=a_{1}+b_{1} z+c_{1} z^{2} \\
C_{\text {inj }}=a_{2}+b_{2} z+c_{2} z^{2}
\end{gathered}
$$

where the coefficients are estimated by statistical methods from the available data. In our application we find that a quadratic function fits the data better over the depth range of interest compared to an exponential function, as discussed in the next section. The model annualizes these up-front fixed costs using amortization factor $A$, which is a function of the discount rate $(r)$ and the project lifetime $(t)$

$$
A=\left(1-\frac{1}{(1+r)^{t}}\right)^{-1} r
$$

Annual O\&M costs are assumed to be $10 \%$ of fixed annual costs based on Bock ((2)), implying that the full average cost function is given by

$$
A C=\frac{1.1 A(r, t)\left(C_{\mathrm{drill}}(z)+C_{\mathrm{inj}}(z)\right)}{Q_{\text {mass }}}
$$

Note that this estimate may be optimistic since maintaining higher pressures for higher injection rates will presumably lead to higher O\&M costs.

\section{Application}

We apply our model to deep saline aquifers in sandstone reservoirs. We evaluate the maximum effective storage potential and injection rate as a function of depth between two end-member cases for a base case set of reservoir properties. The lower end member corresponds to reservoir properties leading to higher costs. (For a full explanation of parameters, see Supporting Information.) We limit our model to a subsurface depth range of between 500 and $3000 \mathrm{~m}$. This range encompasses the shallowest depth at which $\mathrm{CO}_{2}$ is supercritical and the average maximum depth of sedimentary basins in the United States (15). Below this depth, effective storage is constantly decreasing and cost per ton of injection is constantly increasing.

To evaluate the end members for conditions found in sandstone reservoirs, we consider two profiles for temperature and pore fluid density $(6,16$, See Supporting Information for details). High temperature and low fluid density profiles form the constraints for the lower end member and the opposite conditions form the high end member.

We first solve for the effective storage potential given by (4). Upper and lower end members for temperature and pressure as well as the porosity curve are the inputs to this 


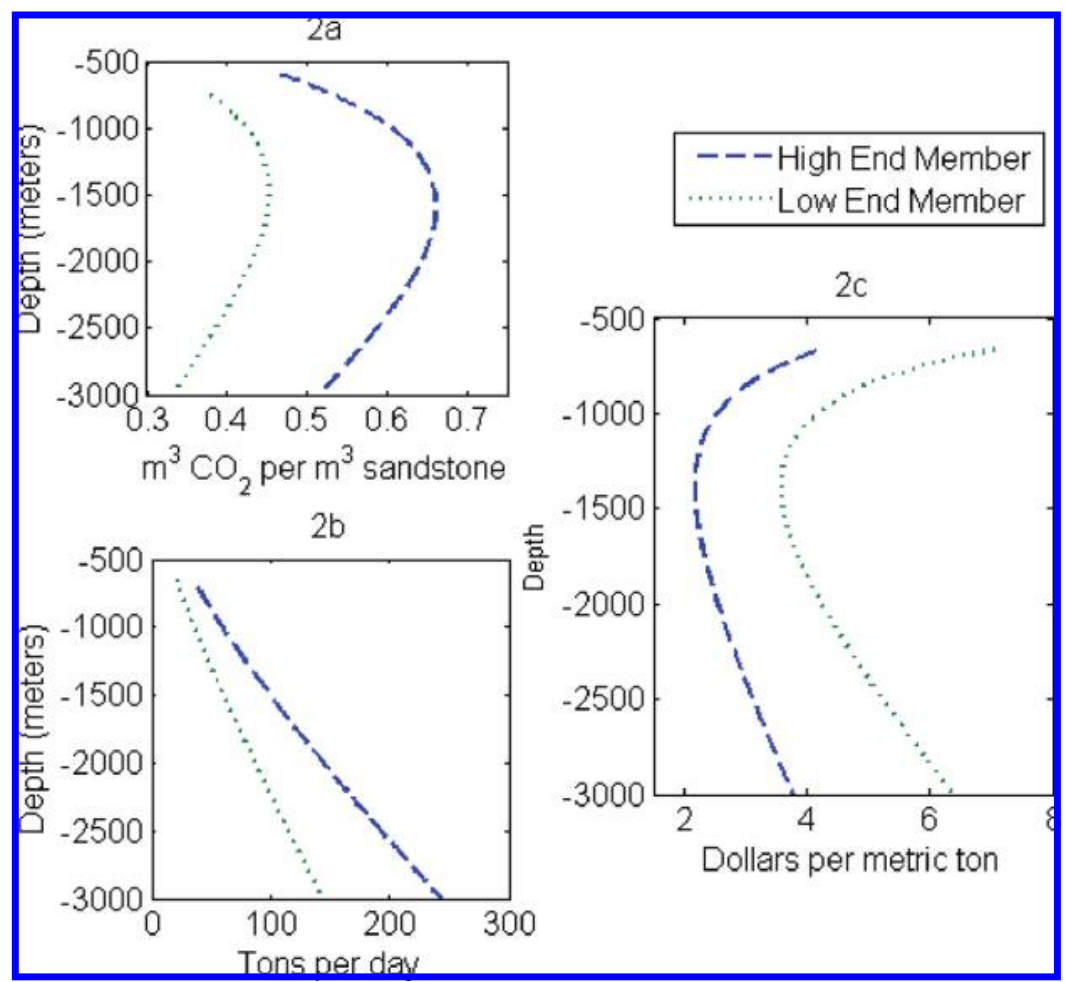

FIGURE 2. Model results. This figure shows the range of effective storage as a function of depth, measured as the volume of $\mathrm{CO}_{2}$ under surface supercritical conditions that would occupy the entire pore space of a cubic meter of reservoir volume (2a), the range of theoretical maximum injection rates in the base-case reservoir permeability and layer thickness ( $2 \mathrm{~b}$ ), and resulting cost per ton of $\mathrm{CO}_{2}$ avoided as a function of depth (2c) with an optimal depth near $\mathbf{1 3 0 0} \mathbf{m}$. The low end member corresponds to high temperatures and low pore fluid density and the high to the opposite.

equation and computed as functions of depth using eqs $1-3$. We determine the maximum injection rate by first solving eqs $5-7$ for the maximum injection well pressure and then use this in eq 14 along with the other inputs from eqs 8-13 to compute the range of theoretical maximum injection rates. We use parameters from the literature $(8,10,17,18$, see Supporting Information) for a base-case reservoir having a thickness of $65 \mathrm{~m}$ and a permeability of $22 \mathrm{md}$. These last two values are based on a compilation of sedimentary basin measurements in the United States assembled by the Texas Bureau of Economic Geology (BEG) (15). We calculate an average (area-weighted) reservoir depth of $1350 \mathrm{~m}$, an average net sand thickness of $65 \mathrm{~m}$, and a log-averaged permeability of $22 \mathrm{mD}$ (however, note that permeability ranges over several orders of magnitude).

The zone of influence term $(f)$ is based on the maximum injection rate which would lead to hydraulic fracturing as reported for the Nagaoka site, which is $48 \mathrm{t} /$ day (19). This estimate yields a value of 0.02 for $f$. We place the lower boundary for injection rate slightly above this in order to make the model more conservative.

Finally, we determine the cost per ton of $\mathrm{CO}_{2}$ sequestered in 2005 dollars as a function of depth from the injection rate. The total capital costs in eq 18 are a combination of drilling costs (eq 15) and injection costs (eq 16). We estimate the coefficients of eq 15 using a quadratic regression on data from the Joint Association Survey on Drilling Costs from 2003 (13), adjusted for increases in drilling costs to 2005 dollars (14). We estimate the coefficients of eq 16 using a quadratic regression on data from the Energy Information Agency (EIA) on injection equipment costs for Enhanced Oil Recovery (EOR) (14), in which we do not include the potential cost of additional compression equipment at the injection site. We calculate an amortization factor to convert this capital cost into the levelized annual cost of this equipment incorporating the discount rate used by the EIA for electricity market modeling of $11.55 \%$ (20) over a project lifetime of 20 years (used by the Electric Power Research Institute in evaluating CCS) (2) in eq 17. Note that the final cost of storage can be highly sensitive to these assumptions; using a discount rate of $10 \%$ over a project lifetime of 25 years, for example, would reduce the amortization factor by $15 \%$. We then calculate cost per ton using the upper and lower bounds on the range of maximum injection rates (per year) with eq 18 .

\section{Results}

4.1. $\mathrm{CO}_{2}$ Storage Potential. According to our model, $0.33-0.66 \mathrm{~m}^{3}$ of $\mathrm{CO}_{2}$ at surface supercritical conditions (or $0.18-0.31$ tons) can be sequestered per cubic meter of reservoir rock in sandstone reservoirs (Figure 2a). Storage varies with depth by approximately the same magnitude as it does between the end members, indicating that at a single spot in a basin there is as much variation with depth as there is among basins at any given depth. The model also shows that the depth at which effective storage potential is optimal is $\sim 1600 \mathrm{~m}$, at which point effective storage ranges between 0.45 and 0.66 .

Our result differs markedly from previous studies (1). While those earlier studies tend to show potential storage increasing monotonically with depth, our model predicts that storage rises to a maximum at intermediate depths and then declines. This behavior arises from nonlinear changes in porosity and from accounting for the counteracting effects of temperature and pressure on fluid density with depth. Note that changes in temperature and pressure lead to slight changes in exactly where the maximum storage occurs (on the order of $100 \mathrm{~m}$ ) but produce significant changes in the actual magnitude of storage potential.

To put this result in context, a minimum of approximately $0.7 \mathrm{~km}^{3}$ of reservoir volume at the optimal depth would be required to store the emissions from a typical $500 \mathrm{MW}$ coal plant capturing 7389 tons of $\mathrm{CO}_{2}$ per day for 20 years with 


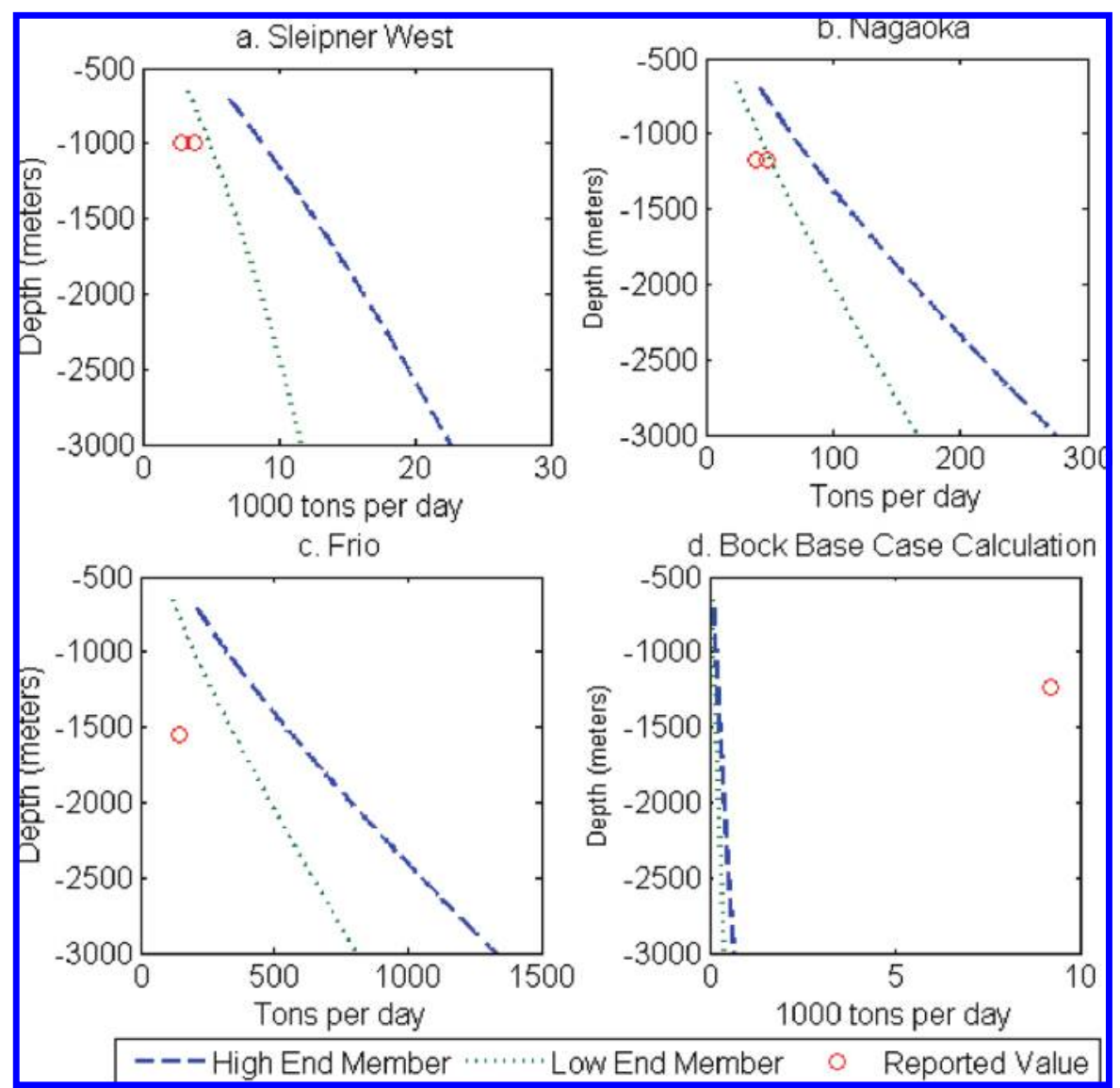

FIGURE 3. Comparison of pilot projects, our model results, and Bock's calculations. This figure shows model runs using permeability and layer thickness values from each project. The reported values of those projects or models are shown in red.

an $80 \%$ capacity factor (2). Note that this is the minimum amount of physical space (i.e., reservoir volume) necessary for storing the $\mathrm{CO}_{2}$. Numerical simulations and pilot projects have indicated that $\mathrm{CO}_{2}$ plume evolution often bypasses the vast majority of this available space. For example, numerical simulations of the Frio injection project have assumed that between $5 \%$ and $30 \%$ of pore space will be occupied (21). If correct, the volume necessary to sequester $\mathrm{CO}_{2}$ will be 3-20 times higher than the minimum predicted by our model.

4.2. Maximum $\mathrm{CO}_{2}$ Injection Rate. In terms of thresholds for maximum injection rates, the model predicts that at the average reservoir depth of $1350 \mathrm{~m} \mathrm{50-80}$ ton $\mathrm{CO}_{2}$ / day could be injected (See Figure 2b). The maximum injection rate increases with depth for two major reasons. First, as depth increases, the threshold pressure for hydraulic fracturing increases, allowing for higher injection well pressures. Second, the density of supercritical $\mathrm{CO}_{2}$ increases with depth, meaning that even constant volumetric flux would lead to higher injection rates at deeper injection depths.

Calibration and comparison of the model results with the Nagaoka, Japan, project and two other projects that have published rates of $\mathrm{CO}_{2}$ injection in deep saline aquifers shows that the lower injection rate seems more reasonable (see Figure $3 \mathrm{a}-\mathrm{c}$ ). As noted previously, only the Nagaoka project has explicitly stated the injection rate that would cause hydraulic fracturing (48 ton $\mathrm{CO}_{2} /$ day (19), Figure $3 \mathrm{~b}$ ). The other two projects cite only actual or designed injection rates, both of which fall below the lower injection rate predicted by our model $(19,21,22)$. That the actual injection rate is below the range predicted by the model may reflect the fact that engineering constraints (e.g., the maximum rate that $\mathrm{CO}_{2}$ can actually be pumped into the well by compressors) and actual reservoir conditions require lower injection rates than the theoretical limits predicted by the model.
4.3. Cost per Ton of $\mathrm{CO}_{2}$ Geosequestration. Our model indicates that the cost of geosequestration is substantial, approximately $\$ 3.50 /$ ton of stored $\mathrm{CO}_{2}$ at the optimal depth (for the model results most closely matching pilot projects). The model predicts $\$ 2-7 /$ ton for the full range of depth and basin characteristics for the base-case permeability and layer thickness (although costs continue to increase at depths greater than $3000 \mathrm{~m}$ ) with an optimum depth near $1300 \mathrm{~m}$. This cost per ton of $\mathrm{CO}_{2}$ stored reflects the injection rate (Figure 2b) and the total cost of injection over the modeled project lifetime, shown in Figure 2c. Recall that we calculate these costs assuming the maximum possible injection rate and storage, meaning that these are minimum theoretical costs.

Lower injection rates at shallower depths mean lower amounts of $\mathrm{CO}_{2}$ stored, so as the amount of $\mathrm{CO}_{2}$ stored increases with depth, cost per ton decreases. However, because the cost of drilling and injection equipment increases in a nonlinear fashion with depth, the decrease in cost gradually peaks at close to $1300 \mathrm{~m}$ in both the upper and lower end-member cases and cost per ton begins to increase monotonically with depth beyond that point.

When we apply the model using the mean depth, layer thickness, and permeability of candidate reservoirs around the United States, we arrive at a much wider variation in the cost of sequestration than our base case, as shown in Figure 4. The figure shows that cost sensitivity to reservoir depth is relatively minor, affecting cost by a factor of up to two. Layer thickness and permeability, however, can potentially increase cost by a factor of 50 when decreased to their lowest limit. Close to the upper limit of permeability, storage costs are pennies per ton, but it is important to note that increasing layer thickness has diminishing returns beyond approximately $1000 \mathrm{~m}$ due to the nonlinear term in drilling costs. 


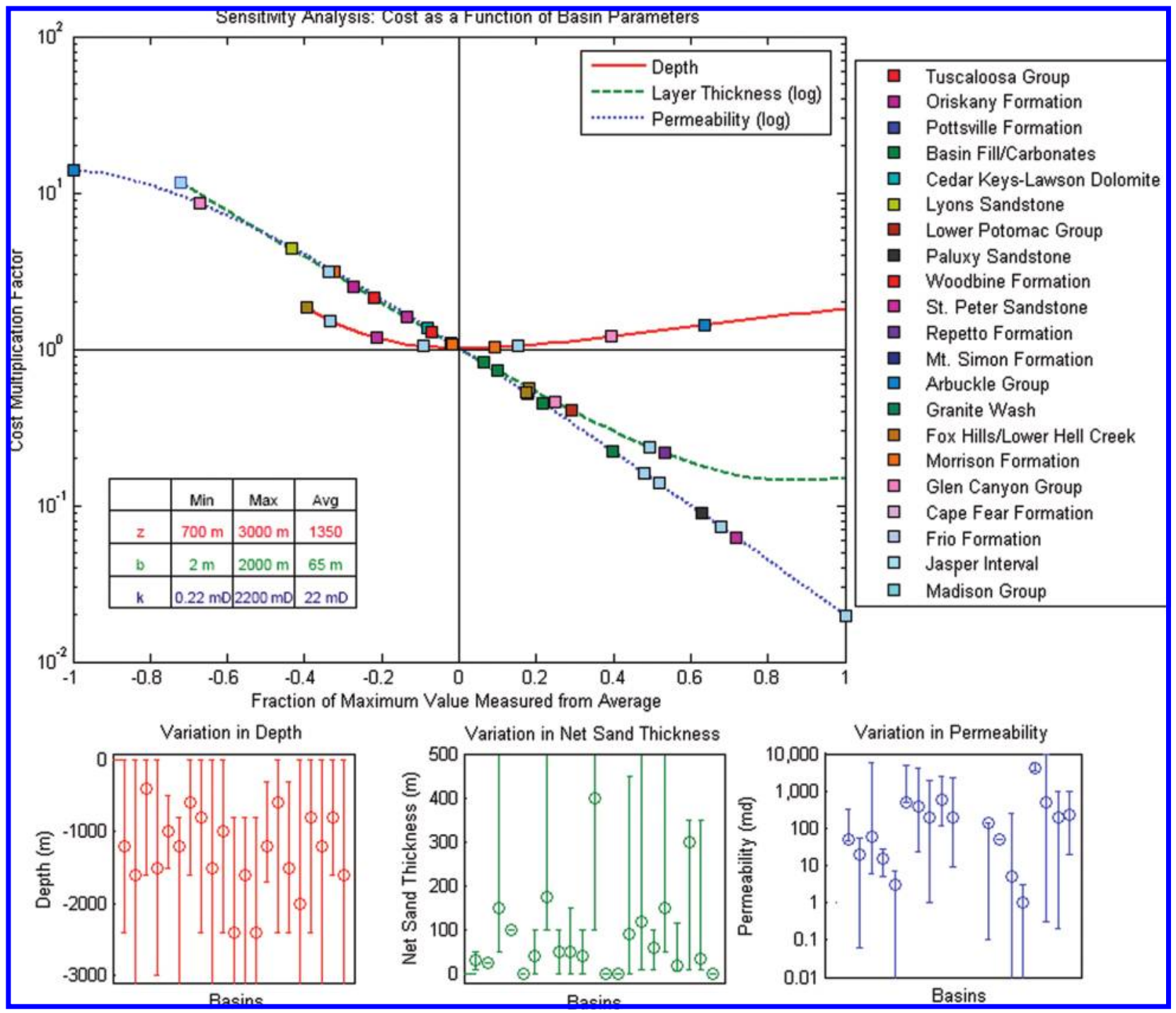

FIGURE 4. Sensitivity analysis: cost as a function of basin parameters. Along the $x$ axis, 0 corresponds to the nondimensionalized base-case values for the reservoir characteristics while minimum and maximum values are scaled to -1 and 1 , respectively (see Supporting Information for conversions). The mean properties of each of the 21 basins from the Texas Bureau of Economic Geology are plotted on this sensitivity analysis, showing that mean properties can and do vary over the whole range considered. Finally, the three panels below this graph show how these properties vary within and among basins. The squares in the top panel correspond to the circles in the bottom three panels.

This indicates that the two factors that have the greatest effect on cost are permeability and layer thickness. All told, cost per ton ranges over almost 4 orders of magnitude for the full range of reservoir characteristics, and these effects compound one another, so real cost will vary over an even wider range.

The range of properties in natural basins actually does vary across the range considered in the sensitivity analysis and in many cases even beyond the extremes, indicating actual costs will similarly vary (see Figure 4). The effect of the distribution of these values on storage cost is shown in Figure 5, which depicts each reservoir evaluated and the maximum, average, and minimum cost per ton for that reservoir. Although the model does not determine whether the factors that would produce these cost estimates occur in the same places, it is a reasonable conclusion that costs even within a single basin will vary from being very inexpensive to prohibitively costly.

\section{Discussion}

The extreme variability in aquifer characteristics means that cost estimates for geosequestration will vary widely around our base-case figure for minimum theoretical costs of $\sim \$ 3.50$ / ton. As noted above, we conclude that it is virtually certain that there are regions in many reservoirs with extremely low injection costs per ton of $\mathrm{CO}_{2}$ sequestered. The most important conclusion of this analysis, however, is that the quantity of storage that could be provided in the low-cost regions is likely to be much lower than the thousands of gigatons often cited as the potential storage capacity of deep saline aquifers (1).

This conclusion arises because the sensitivity analysis shows that there are many regions of major reservoirs that have neither ideal permeability nor ideal layer thickness, leading to higher storage costs than previously projected. Creative engineering such as long-reach horizontal drilling may solve some of these problems, but the cost sensitivity analysis shows the potential limits of that solution; the reduction in cost from effectively extending layer thickness through horizontal drilling to thousands of meters provides diminishing returns due to the higher cost of deeper or nonvertical, longer wells. Since our analysis is performed on a single-well basis, though, we do not account for possible economies of scale in a multiwell system. However, we also 


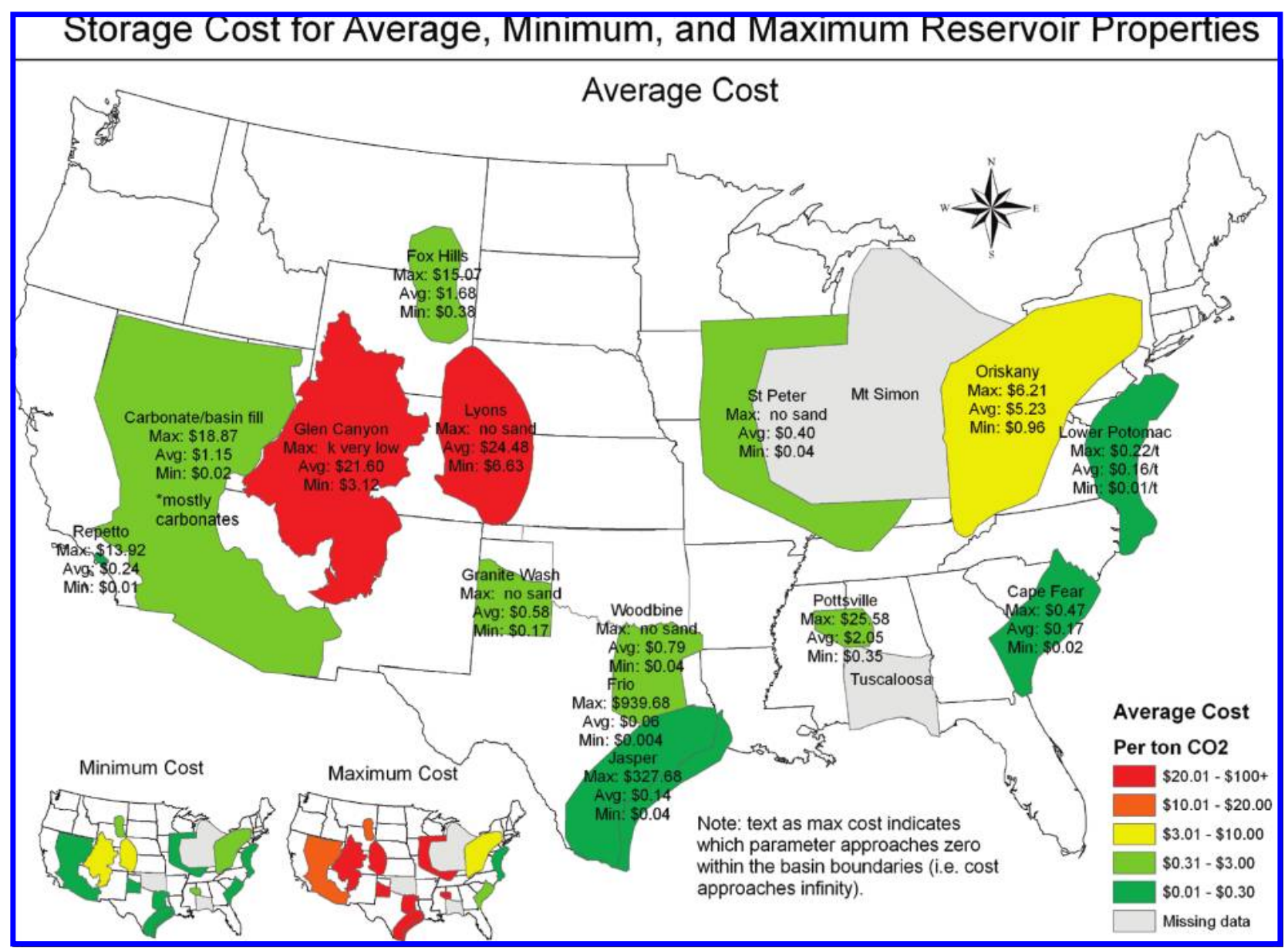

FIGURE 5. Basin average, minimum, and maximum cost per ton of $\mathrm{CO}_{2}$ stored. The model results for the combination of mean depth to formation, net sand thickness, and permeability parameters in each basin are shown in the large map. The parameter combinations that yield the lowest cost and highest cost are shown in the smaller maps. Our analysis does not consider the spatial distribution of reservoir characteristics; it does not asses total storage at any cost level in these basins.

do not account for possible interference between wells in a multiwell system, both of which might affect the economics significantly.

Nonetheless, we can conclude that some tracts of sedimentary basins tentatively identified as having considerable storage potential are unlikely to prove economically viable unless carbon prices support geosequestration storage costs (not including capture and transport) near $\$ 20 /$ ton $\mathrm{CO}_{2}$. It is important to note, however, that these analyses give general estimates for costs of geosequestration and cannot be used as substitutes for a full simulation of a specific site.

Overall, the economics of carbon sequestration depend on many separate cost components, including capture, transport, sequestration, and monitoring. Among those, geosequestration has previously been estimated to be a very minor component of the full cost of CCS. For example, to date, the most comprehensive analysis of geosequestration options in the United States is a report by Bock for the Electric Power Research Institute (EPRI) (2). Bock used a base-case reservoir similar to ours (based on the same BEG data) of $171 \mathrm{~m}$ thickness, $22 \mathrm{mD}$ permeability, and $1240 \mathrm{~m}$ depth (2). The layer thickness, for example, is different because his determination of layer thickness relied on a simple average of formation thickness, not an aquifer size-weighted average of net sand thickness.

More importantly, Bock's report predicts that only one well would be required to inject an average coal plant's output (almost 10000 tons of $\mathrm{CO}_{2}$ per day). This prediction is based on a calculation from a formula derived by Law (11) that relates injection well pressure directly to injection rate. The formula was derived from a regression on a series of results from a numerical simulation designed to estimate the effect of local "sweet spots" on injection rates, not a general rule for relating injection pressure directly to injection rates. The outcome of this simplification is that injection rates calculated by Bock are three times higher than those achieved at Sleipner West, where permeability is 100 times greater than the value used in Bock's calculations (22). With Bock's injection rates, large-scale hydraulic fracturing would result, as shown in Figure 3, which plots actual injection rates at the three pilot projects versus that predicted by Bock. This result suggests that the cost estimates in Bock are too optimistic. The average costs for injection into an aquifer are likely to be over 10 times higher than Bock's estimate of approximately $\$ 0.30$ / ton (2).

Additionally, realistic engineering constraints make injection at very high overpressures unlikely. This is reflected in Figure 3, which indicates that design capacities for injection rates at existing pilot projects are well below the range of theoretical maximum rates predicted by our model. One implication of this conclusion is that the assumption that O\&M costs are a fixed percentage of capital cost is also overly optimistic. These costs will increase as the injection rate increases. Either O\&M costs will need to be reduced by drilling more wells to achieve the same injection rates (increasing capital cost) or higher O\&M costs will arise from having to maintain impractically high injection rates.

In summary, attractive geosequestration opportunities are likely available depending on key characteristics such as 
high average permeability and thick layers at depths conducive to maintaining carbon dioxide in a supercritical state at optimal storage and injection rates. However, these characteristics can vary widely enough to make geosequestration unattractive in many areas of sedimentary basins, changing the nature of the available supply of carbon storage reservoirs in the United States. The focus of our future work will be to identify the portions of specific reservoirs where costs will be lowest and estimate the storage capacity and geosequestration supply curves at these locations.

\section{Acknowledgments}

We acknowledge the support of the Climate Change Policy Partnership for this research.

\section{Supporting Information Available}

Explanation of model parameters. This material is available free of charge via the Internet at http://pubs.acs.org.

\section{Literature Cited}

(1) Intergovernmental Panel on Climate Change: Special report on carbon dioxide capture and storage. Available at http:// www.ipcc.ch/ipccreports/srccs.htm.

(2) Bock, B. Economic evaluation of $\mathrm{CO}_{2}$ storage and sink enhancement options; EPRI, TVA, U.S. DOE: Palo Alto, CA; Muscle Shoals, AL; Washington, DC, 2003.

(3) Hendriks, C.; Graus, W.; van Bergen, F. Global carbon dioxide storage potential and costs; Ecofys and the Netherland Institute of Applied Geoscience, TNO: 2002.

(4) Allinson, W.; Nguyen, G.; Bradshaw, J. The Economics of Geological Storage in Australia. APPEA J. 2003, 623-635.

(5) Bachu, S. Screening and ranking of sedimentary basins for sequestration of $\mathrm{CO}_{2}$ in geological media in response to climate change. Environ. Geol. 2003, 44 (3), 277-289.

(6) Nordbotten, J.; Celia, M.; Bachu, S. Injection and Storage of $\mathrm{CO} 2$ in Deep Saline Aquifers: Analytical Solution for $\mathrm{CO}_{2}$ Plume Evolution During Injection. Transport Porous Media 2005, 58 (3), 339-360.

(7) Athy, L. F. Density, porosity, and compaction of sedimentary rocks. AAPG Bull. 1930, 14 (1), 1-24.
(8) Turcotte, D. L.; Schubert, G. Geodynamics, 2nd ed.; Cambridge University Press: Cambridge, 2002.

(9) Freeze, R. A.; Cherry, J. A. Groundwater, Prentice Hall: Englewood Cliffs, NJ, 1979.

(10) Suppe, J. Principles of Structural Geology; Prentice Hall: Englewood Cliffs, NJ, 1985.

(11) Law, D. H.; Bachu, S. Hydrogeological and numerical analysis of $\mathrm{CO}_{2}$ disposal in deep aquifers in the Alberta sedimentary basin. Energy Convers. Manage. 1996, 37 (6), 1167-1174.

(12) Wiggert, M.C.; Potter, D. C. Mechanics of Fluids, 3rd ed.; Brookes/ Cole Thomson Learning: Pacific Grove, CA, 2002.

(13) Augustine, C. T.; Jefferson W.; Anderson, B.; Petty, S.; Livesay, B. A Comparison of Geothermal with Oil and Gas Well Drilling Costs. Geothermal Reservoir Engineering 31; Stanford University: Stanford CA, 2006.

(14) U.S. Energy Information Agency. Costs and Indices for Domestic Oil and Gas Field Equipment and Production Operations; EIA: Washington, DC, 2007.

(15) Bureau of Economic Geology: Carbon Dioxide Sequestration Study Areas 2000. Available at http://www.beg.utexas.edu/ environqlty/co2seq/co2data.htm.

(16) U.S. Geological Survey. Groundwater Atlas of the United States; USGS: Washington, DC, 1995.

(17) Bahr, D. B. Exponential approximations to compacted sediment porosity profiles. Comput. Geosci. 2001, 27 (6), 691-700.

(18) Fetter, C. W. Applied Hydrogeology, 4th ed.; Prentice Hall: Upper Saddle River, NJ, 2001.

(19) Research Institute of Innovative Technology for the Earth Demonstration Test and Monitoring at the Iwanohara Test Site 2007. Available at http://www.rite.or.jp/English/lab/geological/ demonstration.html.

(20) U.S. Energy Information Agency. The Electricity Market Module of the National Energy Modeling System, EIA: Washington, DC, 2007.

(21) Hovorka, S. D.; Doughty, C.; Knox, P. R.; Green, C. T.; Pruess, K.; Benson, S. M. Evaluation of brine-bearing sands of the Frio formation, upper Texas gulf coast for geological sequestration of $\mathrm{CO}_{2}$. National Conference on Carbon Sequestration 1; National Energy Technology Laboratory: Washington, DC, 2001.

(22) Perkins, E. H. Case Study of $\mathrm{CO}_{2}$ storage in an underground salt aquifer. The Saline Aquifer $\mathrm{CO}_{2}$ Storage Project, 2003.

ES801572E 